\title{
LA DEMOCRATIZACIÓN DE LA GLOBALIZACIÓN: UNA REVISIÓN DEL MODELO COSMOPOLITA DE DAVID HELD
}

\section{THE DEMOCRATIZATION OF GLOBALIZATION: A REVIEW OF DAVID HELD'S COSMOPOLITAN MODEL}

\section{Isabel Victoria Lucena Cid,}

Universidad Pablo de Olavide, Sevilla, España

miluccid@upo.es

Palabras Claves: Estado, política global, globalización, democracia cosmopolita.

Keywords: State, global politics, gobalization, cosmopolitan democracy.

Resumen: La teoría democrática afronta una ineludible tarea frente al imparable proceso de globalización y las consecuencias de su desgobierno. Tras su repentino fallecimiento el pasado mes de marzo, David Held nos ha dejado un interesante y riguroso trabajo sobre el papel de los estados nación en el actual sistema internacional y la viabilidad de la democratización del orden global a través de su modelo democrático cosmopolita. Con nuestra propuesta pretendemos mostrar una visión general de la democracia moderna ante los nuevos retos de la globalización. Seguidamente presentamos los resultados de una investigación sobre el modelo de David Held como una respuesta al des-orden internacional, examinando la deseabilidad y la viabilidad de un orden democrático cosmopolita.

Abstract: The democratic theory faces an inescapable task in front of the unstoppable process of globalization and the consequences of its misgovernment. After his sudden death last March, David Held has left us an interesting and rigorous work on the role of nation states in the current international system and the viability of the democratization of the global order through its cosmopolitan democratic model. With our proposal we intend to show a general vision of modern democracy before the new challenges of globalization. Next, we present the results of an investigation on David Held's model as a response to international dis-order, examining the desirability and viability of a cosmopolitan democratic order. 


\section{l.Introducción}

La idea política de la democracia se encuentra sometida en un serio escrutinio sobre su capacidad para afrontar un contexto mundial sujeto a cambios cada vez más rápidos e inciertos, propiciados por las nuevas condiciones que impone la globalización. Como consecuencia de todo ello, los Estados y las democracias modernas están inmersos en un proceso de transformación del orden internacional sin precedente alguno en la historia.

No existe una definición univoca sobre la noción de "globalización", lo que la convierte en un término muy controvertido con defensores y detractores dependiendo de las connotaciones negativas o positivas de sus características. Durante las dos últimas décadas asistimos a múltiples discusiones académicas en el ámbito de la economía, la ciencia política, el derecho, la antropología, la sociología, etc., constatando que es un tema intensamente disputado y que muchos investigadores discrepan sobre algunos de los aspectos que subyacen en este proceso.

Este desencuentro general se diluye en un punto, casi todos los académicos y analistas están de acuerdo en que la globalización está transformando la configuración moderna de las relaciones internacionales y especialmente el papel del Estado nación en el escenario mundial. Al respecto, Held considera que con "el término "globalización" se señala a la expansión, la magnitud creciente y el impacto cada vez más veloz y profundo de los flujos transcontinentales y de las pautas de interacción social. Se refiere a un desplazamiento en la escala de la organización humana que enlaza comunidades distantes y expande el alcance de las relaciones de poder por todas las regiones y continentes" (Held, 1995). No obstante, esto no significa que los cambios acaecidos hayan traído consigo un mundo más pacífico ni un proceso de integración social global justo.

Sin negar los posibles efectos beneficiosos de la globalización, este fenómeno engendra también profundas divisiones y conflictos que muestran su cara más amarga en muchas partes del planeta. Entre los desafíos que acompañan a la globalización nos encontramos con el cambio climático, la pérdida de biodiversidad y ecosistemas, el agotamiento de los recursos naturales y los problemas asociados a la contaminación. Por otro lado, los datos de los informes del PNUD revelan índices de pobreza cada vez más agudizados y una gran desigualdad mundial; el aumento de conflictos y guerras, el terrorismo, las enfermedades infecciosas que se propagan a gran velocidad, la brecha digital, desastres naturales, tráfico de droga, de armas y de personas, etc. Ante este panorama, ningún Estado tiene capacidad ni potestad suficiente para afrontar y resolver estos problemas mundiales. Necesitamos respuestas comprometidas globales a problemas globales si se quiere encarar adecuadamente estos retos cada vez más apremiantes que se nos presentan.

En este contexto, otro aspecto importante es el incremento de la internacionalización de las actividades nacionales que hace que el papel de los estados en este sistema global sea cada vez más complejo y altere su autonomía (modificando el equilibrio entre los costes y los beneficios de las políticas) y afecte cada vez más a su soberanía (Held, 2007). La progresiva concentración de poder más allá de las fronteras nacionales, el debilitamiento de 
los estados frente a estos procesos y fuerzas del mercado, nos coloca en una situación de riesgo donde la política democrática se va reduciendo para adaptarse a las demandas de los mercados globales (más mercado y menos democracia). Al mismo tiempo, "la susceptibilidad respecto a NNUU en las agenda de los países más poderosos, la debilidad e ineficacia de muchas de sus operaciones de paz y escasa autoridad, la escasa financiación de sus organizaciones, la inadecuada aplicación de muchas leyes medioambientales, nos muestran una eficacia y un alcance muy limitado de la democracia a nivel global. Este escenario sugiere que la política global dependerá cada vez mas de las prioridades económicas globales y de la influencia multilateral de los poderes ejecutivos mundiales (G8-G20)", (Held, 2007).

Tradicionalmente, el estado democrático soberano presuponía la idea de una comunidad que se gobierna directamente a sí misma y determina su propio futuro (Held, 2007). Esta idea está siendo cuestionada, sobre todo por la naturaleza y las complejas interconexiones regionales y globales que destacaba anteriormente. Las comunidades nacionales no tienen la capacidad exclusiva de programar las acciones, decisiones y políticas de sus gobiernos ni asumir las consecuencias que se derivan de estas decisiones de cara a sus ciudadanos. Por todo ello, el significado de democracia, y el modelo de autonomía democrática en particular, deber ser replanteados en relación con el solapamiento de una serie de procesos y estructuras nacionales, regionales y mundiales, (Offe y Preuss, 1991).

La respuesta a esta situación por parte de los defensores y detractores de la globalización es de confrontación teórica y práctica con múltiples manifestaciones ante la cumbre de los principales organismos internacionales (OMC, FMI, BM, Foro Económico de Davos, G-8, G-20, etc.). No obstante, como señala Held, "las perspectivas situadas en los extremos opuestos del espectro político de la globalización -el neoliberalismo y los movimientos antiglobalización-son, ambas, profundamente problemáticas. Mientras el neoliberalismo sencillamente perpetúa los sistemas políticos y económicos y no ofrece solución verdadera alguna a los problemas de fracaso del mercado, la posición radical anti-globalización parece profundamente ingenua en su creencia de un potencial de la acción local para resolver, o competir con la agenda de gobierno generada por las fuerzas de la globalización", (Held, 2007). Ninguna de estas dos posiciones aporta soluciones a los problemas enunciados.

Este trabajo se estructura en tres partes. La primera nos introduce brevemente en la situación en la que se encuentran los Estados nación en el nuevo escenario internacional y el papel de la democracia moderna ante los nuevos retos de la globalización. A través del análisis de recursos bibliográficos y entrevista a David Held, presentamos los resultado de esta investigación abordando el modelo de democracia cosmopolita de Held como una respuesta al desgobierno internacional. Por último, examinamos la deseabilidad y la viabilidad de un orden democrático cosmopolita.

\section{Metodología}

Ante los nuevos desafíos que trae consigo este profundo proceso de transformación internacional nos preguntamos ¿dónde están las instituciones globales capaces 
de regular los excesos de la globalización y la economía mundial en beneficio de todos, capaces de defender a la vez la identidad cultural y la democracia, capaces de combatir tanto el imperialismo de los fuertes como el terrorismo reactivo de los débiles? No existen. ¿Serían necesarias en un estado democrático global? ¿Es deseable esta opción? ¿De dónde extraer los impulsos para avanzar hacia una gobernabilidad democrática de la globalización? ¿Sería viable?

Estas cuestiones sobre el estado nación, la deriva de la democracia representativa, el fenómeno de la globalización y el modelo heldiano de democracia cosmopolita, se han abordado siguiendo una metodología analítica y descriptiva fundamentalmente. La oportunidad de disfrutar de una estancia de investigación de tres meses en el ya desaparecido Global Governance Centre de la London School of Economics and Political Science, dirigido por Devid Held y Mary Kaldor, permitió un acceso directo a las fuentes bibliográficas y, sobre todo, a entrevistas semanales con David Held y a asistir a múltiples seminarios sobre la temática que nos ocupa.

\section{Resultados}

\section{I. Los retos de las democracias ante los desafíos globales}

Para los defensores de la democracia cosmopolita el proceso actual de mundialización no liquida totalmente el Tratado de Westfalia sobre la soberanía estatal, sino que les conmina a las circunstancias históricas, (McGrew, 1997). Keohane por su parte, sostiene que en este orden global postwestfaltiano la noción de soberanía ilimitada, indivisible y exclusiva forma de po- der público, está siendo desplazada por una concepción de una soberanía dividida entre varios organismos - nacionales, regionales e internacionales - y limitada por la naturaleza de su pluralidad (Keohane,1995). De acuerdo con esto, la soberanía se entiende más como un recurso estipulado para una política caracterizada por una compleja red internacional que como un territorio definido por fronteras (Keohane, 2001).

Generalmente, el Estado se define por sus elementos constitutivos: territorio, población, poder y una finalidad. Held lo caracteriza poniendo énfasis en sus aspectos fundamentales, materiales y filosóficojurídicos:

a) Territorialidad. La base física del ejercicio del poder.

b) Control de los medios de violencia. El control del ejercicio de la fuerza dentro del territorio estatal. De modo que se priva al ciudadano de contar con medios para ejercer la violencia, y el estado crea cuerpos armados y policiales para ejercer la fuerza, esta vez legitima.

c) Estructura impersonal del poder. El poder, y las competencias del estado están asignadas y delimitadas por el orden constitucional y legal vigente.

d) Legitimidad. Al ser la condición de existencia estatal la delegación por parte de estos de atribuciones, el Estado debe respetar el pacto social y procurar la satisfacción de los intereses de los súbditos (Held, 2007).

De este modo, la moderna teoría democrática asume y fija una correspondencia entre estado, territorio, nacionalidad, soberanía, democracia y legitimidad. En el ámbito internacional, los estados nacionales mantienen aún un significado político, militar y simbólico importante, pero 
disminuido por las nuevas condiciones asociadas a la globalización, circunstancia que cuestiona y hace dudar sobre la coherencia teórica y empírica de esta presunta correspondencia.

En este sentido, Held identifica importantes desajustes entre la organización de los principios de las democracias liberales y la densa red, regional y global de las relaciones económicas, sociales, culturales, políticas y jurídicas (Held, 1995). Estos desajustes manifiestan el creciente abismo de los estados-nación y los principios de soberanía y autonomía en un sistema global fuertemente interconectado, lo que provoca un crecimiento asimétrico entre el nivel global y transnacional de la vida social y la organización territorial de los gobiernos. Se detecta, pues, una creciente contradicción entre las estructuras internacionales de poder y el proceso de participación, representación, responsabilidad y legitimidad que permanecen aún vinculadas a los aparatos institucionales de los estados (Walker, 1988).

Siguiendo este orden de ideas, nos preguntamos sobre la capacidad de los estados democráticos liberales para seguir funcionando autónomamente en este nuevo contexto. La esencia de la democracia es "el gobierno del pueblo". Cuando un estado afronta problemas como la seguridad nacional, la crisis económica y la degradación ecológica cuyas raíces se encuentran en un plano internacional, las democracias estatales tienen un limitado control sobre las fuerzas que modelan su destino. Si analizamos esta realidad desde el punto de vista histórico, parece que nada de esto es nuevo. Sin embargo, lo que representa una novedad es la densidad y la magnitud de los patrones existentes en la interconexión global. Como hemos visto, la globalización penetra todos aspectos de la actividad so- cial, desde las finanzas a los deportes y de la política a cultura y genera complejas conexiones en todos los ámbitos de la vida, potenciado por las nuevas tecnologías de la comunicación y la información. En este contexto, la capacidad de autogobierno está seriamente amenazada, aunque esto no signifique su extinción.

Si la idea de autogobierno es cada vez más problemática en el contexto de la globalización, más aún lo es el concepto de "demos". El pensamiento tradicional sobre la democracia siempre ha concebido a la comunidad política, al pueblo, como el único que tiene el derecho a autogobernarse. Los miembros de una comunidad política son así definidos, casi exclusivamente, en términos de miembros pertenecientes a un territorio determinado, dentro de las fronteras del estado-nación. En un escenario de estrecha interdependencia e interconexiones globales y regionales, la idea de comunidad política como una unidad de territorio delimitado se está convirtiendo en algo poco convincente y anacrónico. La globalización se teje en un complejo y abstracto sistema en el que el futuro de las gentes, comunidades y pueblos distantes del planeta no pueden ser identificadas en términos de territorio o naciones. Las implicaciones son diversas, en opinión de Held uno no puede comprender la naturaleza y las posibilidades de la comunidad política fijándonos solamente en las estructuras nacionales (Held, 1995). Esto tiene profundas implicaciones para los tradicionales conceptos de consentimiento, legitimidad y responsabilidad, esenciales en las modernas democracias liberales.

Los pensadores democráticos desde J. S. Mill, a Robert Dahl han asumido la simetría entre las instituciones de representatividad democrática y la comunidad po- 
lítica. Los conceptos fundamentales de la democracia son el consentimiento, la legitimidad y la responsabilidad. Según estas nociones los gobiernos dependen del consentimiento de los gobernados. Los ciudadanos, a través de su voto, confieren autoridad a los gobernantes para actuar de acuerdo con el sentimiento de la mayoría. Así, en teoría, los gobernantes permanecen directamente sometidos al "demos" y gobiernan de acuerdo con la expresión general de la soberanía popular. Pero esto supone una correspondencia entre las leyes que gobiernan y los gobernados que cumplen las leyes, una correspondencia que se interrumpe por la existencia de redes regionales y globales y nuevas estructuras de poder deslocalizadas. En estas circunstancias los gobiernos pueden no tener la autoridad suficiente para legislar y decidir en situaciones vitales que pueden afectar la seguridad y el bienestar de sus ciudadanos, mientras que igualmente las consecuencias de las decisiones de los gobiernos puede que no tenga un gran impacto más allá de sus fronteras jurisdiccionales. En definitiva, este sistema global interconectado representa un poder que trasciende las fronteras nacionales y se establece más allá del alcance de los mecanismos nacionales de control democrático.

La democracia moderna, sin embargo, no se puede definir simplemente por sus instituciones y procedimientos, también incorpora las nociones republicanas de "ciudadanos activos", de empoderamiento, participación y comunidad virtuosa. La democracia sustantiva - la realización del bien democrático - es una aspiración incorporada en muchas de las modernas tradiciones del pensamiento democrático del siglo XIX, J.S. Mill, MacPherson, pero la globalización también está transformando y afectando a las condiciones sociales y económicas bajo las cuales la democracia sustantiva tiene que desarrollarse (Held, 1995).

Sobre este aspecto, Sandel argumenta que el sentimiento creciente de desempoderamiento que actualmente aflige a muchos estados democráticos, puede explicarse en base a la desconexión entre el ideal de democracia liberal y la actual organización de la vida social y económica (Sandel, 1996). Las estructuras de poder público y privado se han internacionalizado. Las instituciones internacionales, como el Banco Mundial o la OMC, y corporaciones transnacionales como Microsoft, IBM o el banco de Hong Kong y Shanghái, representan nuevos órganos 0 centros de poder en el orden global. Este poder se está convirtiendo cada vez más en un poder concentrado en corporaciones multinacionales y otros organismos internacionales privados.

Enfrentados a tal concentración de poder, tanto los ciudadanos como los mismos estados democráticos experimentan una sensación de impotencia. Como bien subraya Walker: "el poder está en otro sitio, y es intocable" (Sandel, 1996).

Las consecuencias de esta situación son la erosión del principio de solidaridad social, desilusión por las políticas practicadas por los gobiernos y la despolitización. En estas condiciones el ideal republicano de todos los ciudadanos compartiendo el gobierno de la comunidad política es vacuo ya que este ideal requiere comunidades políticas que puedan controlar sus destinos, y ciudadanos que se identifiquen con esas comunidades para pensar y actuar teniendo como fin hacer realidad el bien común (Sandel, 1996). 
En contraste con esta visión, otros entienden que la globalización parece asociada a un proceso de empoderamiento político y democratizador. En la década de los años 80 los medios de comunicación masivos y globales, así como las nuevas infraestructuras en el ámbito de la información, favorecieron una ola de democratización en muchos países. Se produjo el efecto dominó: la lucha nacional por establecer la democracia en unos países fortaleció la movilización de fuerzas democráticas en otros países. Esto se ve claramente en la revolución democrática que se vivió a partir del año 1989 en los países de Europa del Este, a pesar de los déficits que prevalecen en la actualidad.

Mucho más significativo ha sido, sin embargo, el papel de las instituciones globales y regionales en la consolidación de las democracias liberales. En América Latina, en Asia y África, la transición democrática ha sido propiciada por la influencia de poderosos organismos, en particular el BM, el FMI, y el G7+1, el G20, cuya financiación ha hecho posible, en muchos casos, (a través de condicionalidades políticas y económicas) los procesos de transición democrática y las reformas políticas necesarias para ajustarlas a las economías liberales. Mientras estos objetivos están a menudo en conflicto, estas condicionalidades han logrado una extraordinaria internacionalización y consolidación de los procesos democráticos en muchos países, sin embargo, hay que añadir que no siempre de forma efectivas y sería necesario un análisis de los pros y contras de estas prácticas políticas por parte de los países patrocinadores.

Junto a estas políticas de democratización, hay también una vasta proliferación de iniciativas privadas: ONG, fundaciones, grupos religiosos y asociaciones de derechos humanos que trabajan para fortalecer la floreciente sociedad civil. Estos nuevos esfuerzos han sido interpretados, en algunos casos, como "nuevo imperialismo o colonialismo" de Occidente y el triunfo de la democracia liberal.

La transnacionalización de la actividad política privada se refleja en la emergencia de la llamada "sociedad civil global" (Kaldor, 1998). El avance de la tecnología en el ámbito de las comunicaciones ha favorecido la expansión de las actividades de las organizaciones transnacionales privadas y de los movimientos sociales en todas las regiones del planeta. Entre los grupos más significativo de estas nuevas fuerzas políticas transfronterizas están los movimientos ecologistas, pacifistas, movimientos de derechos humanos, de mujeres, etc. Si bien dentro de las fronteras, en la esfera de la sociedad civil, existen enormes desigualdades entre estos grupos, ya sea en términos de recursos o de accesos a las fuentes del poder, la "sociedad civil global" constituye una constelación de fuerzas políticas cuyo fin es introducir los problemas más urgentes en las agendas internacionales. Las prácticas políticas de todos estos movimientos están construyendo el fundamento de un nuevo modelo de ciudadanía, el cual explícitamente abraza los derechos (y el deber) más allá de las fronteras (Kaldor, 1998).

\subsection{La apuesta por la socialdemocracia cosmopolita de David Held}

La revitalización del interés por la democracia en fechas reciente se ha basado con demasiada frecuencia en una identificación de la democracia con la democracia liberal, en la asunción de que la de- 
mocracia solo puede afectar a los asuntos de gobierno (y no cumple un papel en las esferas social y económica) y en la presunción de que el lugar más apropiado para la democracia es el estado nación.

Entre todas las alternativas que se proponen como respuesta al desgobierno mundial y al papel de los estados nacionales en este nuevo contexto, la social democracia cosmopolita de David Held es una de las propuestas teóricas más elaboradas y que más aceptación tiene en los ámbitos académicos a pesar de las críticas que recibe. El modelo de "socialdemocracia cosmopolita" de David Held aborda los problemas que afrontan las democracias en el contexto de la globalización (Held, 2007). En el núcleo de esta corriente teórica está la creencia de que el patrón actual de globalización y de regionalización está desdibujando las democracias liberales a nivel nacional. En este contexto, las democracias nacionales requieren de una democracia internacional cosmopolita si quieren subsistir y desarrollarse en la era actual. Dicha democracia implicaría el desarrollo de la capacidad administrativa y los recursos políticos independientes en los niveles regional y mundial como complemento necesario de dicha capacidad.

Held constata en sus obras Democracia y Orden Global y Modelos de Democracia la obsolescencia de los principios de autonomía y soberanía tradicional y del concepto de democracia asentado sobre el Estado nación modernos. El concepto de Estado soberano y la idea de gobierno democrático sobre unidades herméticas nunca se han ajustado a la realidad, y menos hoy en día, donde la complejidad relacional ha llegado a niveles inauditos. De esta manera, las comunidades políticas deben ser pensadas no como centros "unidimensionales" de organiza- ción, sino como estructuras formadas por redes de interacción superpuestas. Dada la realidad actual, explicar la naturaleza y las posibilidades de la comunidad política haciendo exclusiva referencia a las estructuras y mecanismos nacionales de poder político no tiene sentido. El principio de autonomía no será efectivo mientras las diversas estructuras de toma de decisiones que afectan a las personas se mantengan ajenas a la posibilidad de deliberación democrática, sin esta posibilidad de dialogo se ve truncada la posibilidad de crear y acceder al debate sobre temas de interés público y con ello la disponibilidad de una estructura de común acción política.

Esta disyuntiva entre la "teoría del estado nación soberano y el sistema mundial contemporáneo, ha traído consigo una notable tensión entre la idea de un estado soberano - centrado en la política e instituciones políticas nacionales- y la naturaleza de la toma de decisiones a nivel internacional. Esto plantea importantes cuestiones acerca de las condiciones en las que una comunidad es capaz de determinar sus propias políticas y direcciones, dadas las limitaciones que impone el orden económico mundial y las normas de funcionamiento de organismos como el FMI, BM y la OMC" a nivel internacional y la UE a nivel regional (Held, 2007).

La importancia de la interconexión e interdependencia de las decisiones en el ámbito internacional no implica, como avanzábamos, que el Estado nación deba desaparecer, sino que estos "dejarían de ser los únicos centros de poder legítimos dentro de sus propias fronteras". De esta forma "el reconocimiento de que ciertas tareas y funciones son y deben ser desempeñadas en y a través de diferentes niveles políticos -local nacional, regional 
e internacional- no entraña que la misma idea de Estado moderno deba extinguirse; significa que esta idea requiere de adecuaciones para poder estirarse a través de las fronteras". Se trata de reorganizar el orden internacional teniendo en cuenta los siguientes requisitos:

i. que los límites territoriales de los sistemas de responsabilidad se reestructuren para que se pueda ejercer un mejor control democrático sobre aquellos asuntos que escapan al control de estado-nación -aspectos de política monetaria, reglas del sistema de comercio global, cuestiones medioambientales, elementos relacionados con la seguridad, nuevas formas de comunicación-.

ii. que el papel y la ubicación de los organismos funcionales y reguladores en los niveles regional y mundial sean replanteados para que puedan proporcionar un enfoque más coherente con los asuntos políticos.

iii. Integrar al proceso democrático a los grupos, agencias, asociaciones y organizaciones de la economía y de la sociedad civil (Held, 2007).

De este modo, los asuntos que corresponderían a las asociaciones más cercanas a las bases, nivel local, comunidades o de trabajo, son "aquellos que involucran a las personas en la determinación directa de las condiciones de su propia asociación", es decir que afectan a las personas de manera más inmediata. A su vez los niveles nacionales de gobierno se deberían ocupar de los "problemas colectivos que afectan a una población en particular sin llegar a cruzar las fronteras de su territorio". A los niveles regionales les corresponderían aquellos asuntos "que exigen mediación transnacional a causa de la interconexión de las decisiones y las consecuencias nacionales". Por tanto, el nivel internacional debiera tomar las decisiones que por su marco de influencia o asuntos a los que hacen frente, escapen de la competencia de los otros niveles, es decir, aquellos que sólo pueden ser resueltos eficazmente desde una perspectiva global.

A través de estos marcos de decisión política se distribuirían los campos de acción de acuerdo a un criterio de eficiencia, según el cual los asuntos que puedan ser tratados eficazmente por un nivel inferior serán resueltos a ese nivel sin necesidad de elevarse a nivel contiguo. La actuación en los distintos niveles han de ser articulados coherente y simultáneamente en relación con los temas que lo requieran (asistencia humanitaria en situaciones de inseguridad humana por catástrofes, conflictos o guerras: emergencias medioambientales, crisis económicas, etc. Nuestro autor, considera esencial la creación de un poder ejecutivo y legislativo transnacional, efectivos tanto en el plano regional como en el global, sujeto por las disposiciones del derecho público democrático. Esto implicaría la creación de parlamentos regionales y la confirmación de los existentes, para que "sus decisiones sean reconocidas como fuentes independientes y legítimas de la regulación regional e internacional" (Held, 2007).

Se contempla, además, la posibilidad de efectuar referéndums internacionales, donde la sociedad civil se pronunciaría sobre las discrepancias que pueden existir entre las prioridades de las decisiones internacionales. A su vez, sería también necesaria la implementación de "una asamblea que reuniera a todos los Estados y agencias democráticas" dotada de una real capacidad de acción política, donde sus miembros sean elegidos y con- 
trolados directamente por la población. Esta asamblea, una vez constituida, sería el centro de discusión y de decisión política de todos los problemas globales como las enfermedades, la desnutrición, la deuda del tercer mundo, los problemas medioambientales, etc. En este sentido se presentan tres niveles de exigencia; inmediatos, a mediano plazo e ideal (Held, 1995, 2007).

En materia de seguridad, Held plantea que una parte de las fuerzas militares de cada Estado nación podrían ser asignadas a la autoridad trasnacional, conformando todas las unidades un bloque coherente de mando centralizado. Otra posibilidad que plantea es la creación de una fuerza militar independiente conformada por voluntarios de todos los países. Las dificultades e inconvenientes de implementar tamaña fuerza, al menos bajo las condiciones estratégico-militares existentes hoy por hoy, hacen que Held estime como solución más oportuna y eficiente el desarme en el mayor grado posible de las naciones, y después implementar un nuevo modelo de fuerzas de seguridad, o la centralización del mando de todas las fuerzas estatales en un comando supranacional militar, lo que supone que todas ellas obedecen a una misma autoridad o superior jerárquico.

En el ámbito de la economía se insta a la regulación internacional del sistema financiero y económico. En la actualidad este aspecto de la vida internacional tiene una gran influencia y poder como elemento configurador del orden político, además de constituir un eje articulador de la vida social. Es imposible soslayar la relevancia de esta esfera en todo proyecto político, más aun si lo que se pretende es una reconfiguración del orden internacional. En términos generales, podemos decir que la economía responde a un orden derivado de la asimilación plena de las consecuencias de las decisiones económicas y de la búsqueda de satisfacción de estándares en cuanto a condiciones materiales de vida y de preservación medioambiental. De este modo se insta a una reorientación respecto de lo que ocurre actualmente respecto de la descentralización de las decisiones económicas, esto es, las decisiones tomadas por un agente económico en base a los principios de utilidad y beneficio que da lugar a un injusto desorden desde el punto de vista global, dado que sus decisiones no se corresponden con la responsabilidad de las consecuencias económicas que éstas provocan. Esta manera de entender la economía y sus nefastas consecuencias se ha visto claramente durante la crisis económica y financiera desatada en 2008. Ante esta realidad, Held ofrece una crítica de la globalización económica neoliberal por mantenerse al margen de la realidad social, generando muchas de estas decisiones irresponsables, cuyo objetivo principal se centra en beneficiar a las grandes corporaciones; por ser insostenible ambientalmente y por aumentar, o al menos mantener, el estado de desigualdad dentro de los estados y entre los pueblos del mundo.

En el modelo cosmopolita de Held, la economía y las decisiones de los agentes económicos serian tomadas dentro de un marco de plena recepción de los riesgos/ externalidades y teniendo en cuenta la finalidad general que será la que guíe las decisiones económicas. No sería un sistema de planificación económica centralizada a la usanza de las economías marxistas, pero las decisiones económicas serian tomadas en un plano de adecuación a las necesidades planetarias y definidas en un contexto democrático. 
Las propuestas más relevantes de la socialdemocracia cosmopolita de David son:

a) Asamblea autorizada de todos los estados y agencias (una especie de Asamblea General NNUU, su objetivo sería examinar los problemas más acuciantes. Su misión sería establecer mediante leyes marco, las normas e instituciones necesarias para integrar la legalidad, los principios democráticos y las condiciones mínimas para el florecimiento de la humanidad (Held, y Koenig-Archibugi, 2005).

b) Parlamentos regionales y estructuras de gobiernos en todos los niveles.

c) Posibilidad de que el publico examine el funcionamiento y participe en el estableciendo de la agenda de organizaciones gubernamentales internacionales.

d) Crear nuevas estructuras de gobiernos globales con responsabilidad para solucionar la pobreza y generar bienestar.

e) Mejorar la trasparencia y responsabilidad de las organizaciones de la sociedad civil, nacionales e internacionales, corrigiendo posibles efectos perturbadores.

f) Elaborar consultas o referendos generales transnacionales a nivel regional o global en el caso de prioridades dudosas sobre la implantación de empresas cosmopolitas.

g) Desarrollar competencias legales coercitivas, incluyendo el mantenimiento de la paz para luchar contra las amenazas graves a nivel regional o global. Es necesario desterrar la inquietud, ante las acuciantes y violentas amenazas para los derechos humanos fundamentales y las prioridades democráticas (Held, y Koenig-Archibugi, 2005).

\section{Discusión y conclusión: ¿Es la democracia cosmopolita una alternativa viable?}

El proceso de globalización ha puesto en evidencia no solo la capacidad humana para lograr grandes avances en materia científica y tecnológica que facilita las condiciones de vida de millones de personas en el mundo, sino que ha demostrado también su faceta más oscura: la reducción de la capacidad de control sobre los fenómenos políticos, sociales, económicos o culturales que tienen lugar en un estado determinado, las escandalosas desigualdades planetarias dan fe de ello. Falk define estas desigualdades como apartheid global (Falk, 2002). La migración, asociada a la pobreza, sigue siendo perseguida a gran escala y no existen mecanismos planetarios de redistribución de la renta, el agotamiento de los recursos naturales y energéticos, la degradación medioambiental, el calentamiento global y el consecuente cambio climático, la desertificación, el efecto invernadero, la lluvia ácida, la disminución de la capa de ozono y extinción de miles de especies, etc., son ejemplo de ello (Falk, 2002).

Teniendo como marco esta situación, la democracia cosmopolita de David Held persigue la ampliación y el desarrollo de las instituciones democráticas en los niveles regional y mundial como complementos necesario de las políticas nacionales. Held deja muy claro que esta concepción de la democracia se basa en el reconocimiento de la persistente importancia de los estados nacionales, aunque a la vez abogue por una esfera de gobierno que imponga una limitación a la soberanía nacional. Igualmente, defiende la autonomía del estado 
para llevar a cabo objetivos políticos. En el ámbito regional e internacional aboga por los fortalecimientos de la capacidad administrativa y la responsabilidad de las instituciones regionales y del sistema de NNUU. No solo "se trata de definir formalmente nuevas instituciones democráticas sino definir también amplias vías de participación cívica en la deliberación y la toma de decisiones a nivel nacional, regional y mundial. La viabilidad de la democracia pasa hoy por un marco ampliado de instituciones y organismos democráticos" (Held, 1995 y 2007)

La social democracia cosmopolita representa, pues, una propuesta de reorganización jurídica-política a nivel global en un mundo cada vez más complejo e interdependiente y carente de formas efectivas de articulación de las políticas a nivel planetario. Procura alimentar algunos de los valores más importantes de la social democracia y aplicarlos a la nueva constelación global de la economía y la política. Las negociaciones sociales nacionales, como ya hemos anotado, son insuficientes para asegurar un compromiso equilibrado entre la eficiencia de los mercados y los valores de la comunidad social y la política de la democracia. Es una base para promover el imperio del Derecho internacional; mayor trasparencia, capacidad de rendición de cuentas y democracia en el gobierno global; un compromiso más profundo con la justicia social, la protección y reinvención de la comunidad en distintos niveles, y la transformación de la economía global en un orden económico libre, fundado en normas y equilibradamente justo. La política de la social democracia contiene claras posibilidades de diálogo entre diferentes segmentos de las políticas "pro-globalización / anti-globalización".
La democracia cosmopolita es un proyecto cultural y político, pero con una diferencia: está mejor adaptado y es más adecuado a nuestra época global. El desafío es grande pero también lo son los potenciales beneficios para la seguridad y el desarrollo humano. En este sentido, Held sostiene que "fijar una nueva agenda no supone resolver todas la profundas y persistentes dificultades a las que se enfrenta la teoría y la práctica democrática. Pero es de esperar, al menos que hayamos abierto una vía para la profundización y la ampliación de la democracia en y entre los países, un desarrollo esencial si se pretende que a democracia mantenga su relevancia, su eficacia y su legitimación en el futuro" (Held, 2007).

Para empezar a construir una alianza convincente que nos conduzca a la social democracia cosmopolita de David Held hay que emprender algunas acciones que podemos formular así:

- Las potencias europeas líderes necesitan comprometerse con la creación de un orden multilateral, y no de uno multipolar donde meramente procuran defender sus propios intereses estatales antes que otra cosa.

- La Unión Europea debe resolver su débil capacidad estratégica y geopolítica con el desarrollo de una fuerza de reacción rápida y la creación de unas fuerzas armadas europeas.

- Estados Unidos necesita reconocer que sus intereses estratégicos, económicos y medioambientales de largo plazo sólo se pueden conseguir en colaboración, y que tiene que aceptar, como cuestión de principios, las oportunidades y límites que le ofrecen instituciones multilaterales y regímenes internacionales.

- Los países en desarrollo, que están en busca de mayores inversiones del 
exterior y mejor asistencia (públicas y privadas), necesitan aceptar el establecimiento de un gobierno trasparente como parte de los requisitos para atraer inversiones en la infraestructura de sus economías y sociedades.

- Las organizaciones internacionales gubernamentales necesitan comprender que, si bien sus voces importan en los asuntos globales, representan intereses particulares que se deben articular en estructuras más amplias de rendición de cuentas y justicia.

- Las organizaciones internacionales no gubernamentales que utilizan y solicitan mayores recursos públicos tienen que reconocer que son parte de un servicio civil internacional que ofrece bienes públicos centrales -y que no son avanzadillas de ciertos Estados Nación-.

- Las estructuras regionales de gobierno, si bien potencian y expanden las oportunidades de desarrollo de sus estados miembros, deben comprometerse a mantener abiertas las regiones para que puedan vincularse económica y diplomáticamente con otras. En pocas palabras, necesitan alentar y abrigar formas abiertas de regionalismo.

- Los gobiernos nacionales deben reconocer que son accionistas en problemas globales, los parlamentos nacionales y regionales necesitan potenciar su comunicación, comprensión y compromiso con el gobierno supranacional (Held, 2004).

Las críticas que han recibido las diversas propuestas de una democracia global pretenden poner de manifiesto las dificultades que afronta la realización de un modelo como este. La mayoría de estas críticas provienen del realismo político y sus seguidores, pero no sólo de ellos. Sin embargo, hemos de subrayar que la esen- cia de la crítica que el realismo hace al proyecto de una "democracia global" tiene que ver con una cuestión de poder, se trata de poder vs derecho. En un sistema internacional como el actual, dominado por unos pocos y grandes poderes, sin un aparato internacional de coacción, ¿cómo se puede realizar una transición hacia un orden mundial más democrático sin la tácita aceptación de países que mantienen un papel preponderante en el mundo actual y otros poderes económicos y financieros? Este es el mayor impedimento a la democratización del orden internacional.

La democracia global puede ser un proyecto racional y deseable, pero como observaba Rousseau dos siglos atrás, si el proyecto permanece irrealizado, esto no es porque sea una utopía, es porque los hombres están locos, y porque estar sano en un mundo de locos, es asimismo una clase de locura (Rousseau, 1998).

\section{Bibliografía}

Archibugi, D. (1995) "Inmanuel Kant, cosmopolitan law and peace", en European Journal of International Relations, 1 (4)

Barber, B. (2007) Globalizing Democracy. www.openDemocracy.org (Febrero)

Beck, U. (2002) La Sociedad del Riesgo. Barcelona: Editorial Paidós,

Beck, U. (1997) ¿Qué es la globalización? Barcelona: Editorial Paidós,

Beck, U. y Beck-Gernsheim, E. (2003) La Individualización, Barcelona: Editorial Paidós

Breenan, T., (2002) "InternacionalismCosmopolitanism", en Debating Cosmopolitics, London: Editorial Verso

Brunner, J. J. (1998) Globalización cultural y Posmodernidad. Santiago: Editorial FCE 
Burnheim, J., (1995) Is Democracy Possible? Cambridge, Cambridge University Press,

Burnheim, J., (1996) "Democracy, nationstates and the world system" en D. Held and C. Pollitt (Eds.) News forms of Politics. London: Sage

Burnheim, J., (1995) "Power-trading and the environment" en Environment Politics 4 (4) 44-65

Chomsky, N., (1996) Dieterich. Heinz, La Sociedad Global, Santiago: Editorial LOM

Commission on Global Governance, (1995) Our Global Neighbourhood. Oxford. Oxford University Press

Connolly, W. E., (1995) Democracy and territoriality, Millennium, 20 (3) 463-84

Crawford, J., (1994) Democracy in International Law. Cambridge. Cambridge University Press

Dryzek, J. S., (1995) "Political and Ecological Communication" en Environmental Politics, 4 (4) 13-30

Falk, R., (2002) La Globalización Depredadora. Buenos Aires: Editorial Siglo XXI

Falk, R., (1995) "Liberalism at the global level: the last of the independent commission?" en Millennium, 24 (3) 563-78

Falk, R, (1987) "The global promise of social movements: explorations at the age of time?" en Alternatives, 12 (2) 173-96

Fine, R., (2004) "Cosmopolitanismo sin "ismo": Un ensayo reconstructivo", en Revista Persona y Sociedad n ${ }^{\circ} 2$, Universidad Alberto Hurtado.

Held, D., (1991) "Democracy, the nationstate, and the global system" en Held, D. Political Theory Today, Cambridge, Polity Press

Held, D., (2004) Social Democracia Global. Foro de Altos Estudios Valparaíso, Chile Held, D., (1995) Democracy and the global order, Cambridge, Polity Press
Held, D., (2007) Modelos de Democracia, Madrid: Alianza Editorial

Held, D., \& McGrew A, (Eds.) (2002) The Global Transformations, Reader. An Introduction to the globalization debate. Oxford, Blackwell Publishers

Held, D., \& McGrew A, (Eds.), (2002) Governing Globalization. Power, Authority and Global Governance. Oxford, Blackwell Publishers

Held, D. \& Koenig-Archibugi, M, (Eds.), (2005) Global Governance and Public Accountability. Oxford, Blackwell Publisher

Held, D., (2002) La democracia y el orden global. Barcelona: Editorial Paidós

Himmelfarb, G., (1999) "Las ilusiones del cosmopolitanismo" en Los límites del Patriotismo. Buenos Aires: Editorial Paidós

Hobbes, T., (1989) Leviatán. Madrid: Editorial Alianza

Kaldor, M., (2003) La sociedad civil global, Barcelona: Tusquets

Kaldor, M., (1998) News and Old Wards, Cambridge: Polity Press

Kant, I., (2001) Sobre la paz perpetua. Madrid: Alianza Editorial

Keohane, R. O., (2001) EGovernance in a Partial Globalized World", American Political Science Review, Presidencial Address, 95 (1) pp. 1-13

Keohane, R. O., (1995) “Hobbes' dilemma and institutional Cahnge in World Politics: Sovereignty in International Society", en Holm, H. and Sorenson, G. (Eds) Whose World Order? Boulder: Westview Press

Linklater, A., (1996) The archievement of critical theory. In S. Smith, K. Booth and M. Zalewski (Eds.) International theory: Positivism and Beyond, Cambridge University Press

Linklater, A., (1996) "Citizenship and sovereignity in the post-Westphalian state" en European Journal of International Relations, 2 (1) 77-103 
Martínez, D. y Vega Ruiz, M. L., (2001) La globalización gobernada. Estado, Sociedad y Mercado, Tecnos, Madrid

McGrew, A., (1997) The transformation of democracy? globalization and territorial democracy, Cambridge; Malden, MA: Polity Press

Nayyard, D., (2002) Governing globalization. Issues and Institutions. Oxford, Oxford University Press

Offe, C. y Preuss, U., (1991) "Democratic institutions and moral resources" en Held, D. (Ed.) Political Theory Today, Cambridge: Polity Press

Pianta, M., (2002) “Democracy vs. Globalization. The Growth of Parallel Summits and Global Movements" en Debating Cosmopolitics. Editorial Verso London

Rousseau, J.J., (1998) El contrato social, Madrid: Alianza Editorial

Sandel, M., (1996) Democracy's Discontent, Cambridge. Mass. Harvard University Press

Sartori, G. y Mazzoleni, G., (2003) La tierra explota: Superpoblación y desarrollo, Madrid: Taurus

Urbinatil, N., (2002) "Can Cosmopolitical Democracy be Democratic? en Debating Cosmopolitics. London: Editorial Verso

Walker, R. B. J., (1998) One World, many Worlds: Struggles for a Jus World Peace. Boulder: Lynn Rienner 